\title{
Progress Toward a Stabilization and Preconditioning Protocol for Polycrystalline Thin-Film Photovoltaic Modules
}

Joseph A. del Cueto, Chris A. Deline, Steve R. Rummel, and Allan Anderberg

Presented at the $35^{\text {th }}$ IEEE Photovoltaics Specialists Conference Honolulu, Hawaii

June 20-25, 2010

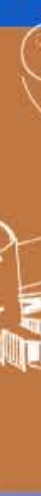




\section{NOTICE}

The submitted manuscript has been offered by an employee of the Alliance for Sustainable Energy, LLC (Alliance), a contractor of the US Government under Contract No. DE-AC36-08GO28308. Accordingly, the US Government and Alliance retain a nonexclusive royalty-free license to publish or reproduce the published form of this contribution, or allow others to do so, for US Government purposes.

This report was prepared as an account of work sponsored by an agency of the United States government. Neither the United States government nor any agency thereof, nor any of their employees, makes any warranty, express or implied, or assumes any legal liability or responsibility for the accuracy, completeness, or usefulness of any information, apparatus, product, or process disclosed, or represents that its use would not infringe privately owned rights. Reference herein to any specific commercial product, process, or service by trade name, trademark, manufacturer, or otherwise does not necessarily constitute or imply its endorsement, recommendation, or favoring by the United States government or any agency thereof. The views and opinions of authors expressed herein do not necessarily state or reflect those of the United States government or any agency thereof.

Available electronically at http://www.osti.gov/bridge

Available for a processing fee to U.S. Department of Energy and its contractors, in paper, from:

U.S. Department of Energy

Office of Scientific and Technical Information

P.O. Box 62

Oak Ridge, TN 37831-0062

phone: 865.576 .8401

fax: 865.576.5728

email: mailto:reports@adonis.osti.gov

Available for sale to the public, in paper, from:

U.S. Department of Commerce

National Technical Information Service

5285 Port Royal Road

Springfield, VA 22161

phone: 800.553.6847

fax: 703.605.6900

email: orders@ntis.fedworld.gov

online ordering: http://www.ntis.gov/ordering.htm 


\title{
PROGRESS TOWARD A STABILIZATION AND PRECONDITIONING PROTOCOL FOR POLYCRYSTALLINE THIN-FILM PHOTOVOLTAIC MODULES
}

\author{
Joseph A. del Cueto, Chris A. Deline, Steve R. Rummel, Allan Anderberg \\ National Renewable Energy Laboratory, Golden, CO, United States
}

\begin{abstract}
Cadmium telluride (CdTe) and copper indium gallium diselenide (CIGS) thin-film photovoltaic (PV) modules can exhibit substantial variation in measured performance depending on prior exposure history. We studied the metastable performance changes in these PV modules with the goal of establishing standard preconditioning or stabilization exposure procedures to mitigate measured variations prior to current-voltage (IV) measurements. We present the results of our case studies of module performance vs. exposure: light-soaked at $65^{\circ} \mathrm{C}$, exposed in the dark under forward bias at $65^{\circ} \mathrm{C}$; and finally longerterm outdoor exposure. We find that stabilization can be achieved using either light or dark bias methods. Additionally, we performed and present capacitancevoltage profile measurements on the modules to examine the changes in depletion widths or its hysteresis plus electronic carrier concentrations as a function of exposure.
\end{abstract}

\section{INTRODUCTION}

Short-term transient increases in the open-circuit voltage $\left(\mathrm{V}_{\mathrm{OC}}\right)$ of $\mathrm{CdTe}$ and $\mathrm{ClGS}$ devices have been observed after illumination or forward bias [1]. These persist on time scales spanning seconds to hours. Longer-term metastable changes in the electrical characteristics of CdTe modules have also been observed under illumination [2], occurring over time scales of a thousand hours (h) of exposure at 1-sun. These effects can reverse subsequently when the modules are put into dark storage-defined as low light level conditions at room temperature-in periods of days to weeks. Transient changes in CdTe devices have also been observed to occur on time scales of days, attributed to changes in electronic states and recombination [3]. In CIGS devices, reversible changes in fill factor (FF) and $V_{O C}$ are observed when devices are measured after voltage bias or lightsoaking [4]. These or other metastable changes have been attributed to persistent photoconductivity due to copper migration [5], charging-discharging of donors at the CdS/CIGS interface and deep acceptors in CIGS [6], and selenium-copper vacancy complexes [7]. In CIGS devices, thermal exposure such as during damp heat stress $\left(85^{\circ} \mathrm{C}\right)$ appears to generate changes in both the absorber and interface, which diminish the FF and $V_{O C}[8,9]$, although in these references, exposures were conducted in unencapsulated devices. Most of the losses appear to be reversible with subsequent light-soaking in CIGS modules [10]. In CdTe devices, when copper (Cu) is added to the back contact, device performance improves, but it introduces metastability issues $[11,12]$.
These transient or metastable effects pose a challenge when trying to accurately gauge PV module performance, such as during sampling from the production stream or in module certification tests. The current certification standard for thin-film PV modules-IEC 61646 [13]prescribes successive light-soaking increments of $43 \mathrm{kWh} / \mathrm{m}^{2}$ integrated irradiance until the relative changes in measured power are $2 \%$ or less. This procedure was designed more toward amorphous silicon, and is quite likely not optimal for stabilizing polycrystalline CdTe or CIGS PV devices. Moreover, it appears very probable that in CdTe and CIGS, there are multiple ranges of time scales over which transitory effects in electrical characteristics may take place-short times on the order of minutes to hours, and much longer time scales like weeks or more. The different time scales probably emerge via disparate mechanisms. For example, carrier traps are likely responsible for short-term transients, whereas species migration may be responsible for metastability. In this paper, we refer to the short- or longer-time scale effects as transient or metastable, respectively.

Our goal is to devise a set of procedures suitable for stabilizing the measured performance in CIGS and CdTe PV modules, so that measurements made either after dark storage, manufacture, or certification will be reproducible to within allowable tolerance. Because there seem to be short- and long-term evolution of measured performance, it may be necessary or useful to consider separate procedures: one for preconditioning, or removing the transient effects; plus a second that addresses stabilizing the module to its long-term performance measured when deployed outdoors. We undertook the latter task and considered alternate stabilization paths: light-soaking at 1-sun or forward biasing in the dark, as suggested in the literature [1, 3, 4], carried out at elevated temperatures.

\section{EXPERIMENT}

A flow chart of our experimental study plan is shown in Fig. 1, indicating baseline, preconditioning, and then the main sequence of either light-soaking or forward bias in the dark, both at nominally $65^{\circ} \pm 5^{\circ} \mathrm{C}$ module temperature, as alternate exposure paths carried out in weatherometer chambers indoors. Prior to the main stabilization sequence, we exposed modules under natural outdoor lighting at open-circuit for two short-time increments$1 \mathrm{kWh} / \mathrm{m}^{2}$ and $26 \mathrm{kWh} / \mathrm{m}^{2}$ - to study if that produces adequate, feasible preconditioning, as indicated at the top portion of the figure. Afterward, if individual modules passed minimum performance quality, they underwent dark, thermal anneal at $90^{\circ} \mathrm{C}$ for $48 \mathrm{~h}$, nominal $\mathrm{RH}$ 
$(\sim 30 \%)$, and open-circuit, in one of the chambers, prior to indoor stabilization. This dark thermal anneal is expected to 'relax' some of the changes caused by stress or exposure. At baseline and after each exposure, dark and light I-V measurements were conducted. Moreover, because it's been proposed that hysteresis in the depletion width vs. voltage bias profile derived from capacitance-voltage $(\mathrm{C}-\mathrm{V})$ profile measurements may correlate with CdTe device stability [12], we measured C-V profiles at various stages of exposure.

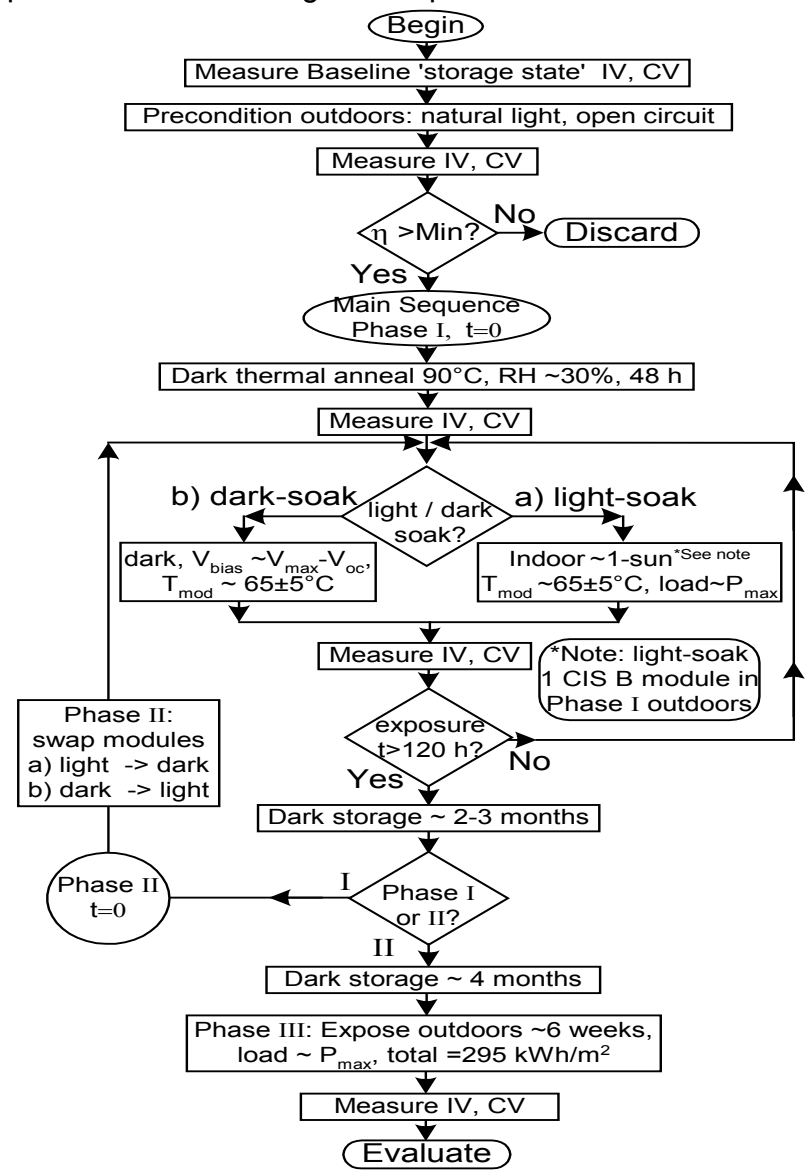

Figure 1 Stabilization study plan flow chart.

After dark, thermal anneal, we began phase I of the study. It's worth pointing out that in phase I, to prevent module damage, a conservative value of forward bias voltage was applied halfway between Voc and the maximum-powerpoint voltage, which generates substantially less than the maximum-power-point current (I IMPP). In phase II, we applied larger voltages to get up to the IMPP, during dark exposure. This probably made a substantial difference in the rate at which we drove module stabilization. Also in phase I, we ran four voltage-biased, dark exposures but five light-soak ones. In phase II, we ran three 48-h increments each of light and dark exposures. Exposures carried out indoors were performed in 24- or 48-h increments, after which I-V and $\mathrm{C}-\mathrm{V}$ measurements were conducted. After accumulating $\sim 120 \mathrm{~h}$ of total exposure, phase I ended and the modules lay in dark storage for 2 to
3 months, after which they were re-tested (I-V, C-V). Then phase II began with most of the same modules, except that the modules were swapped with respect to indoor exposure: those that had been light-soaking in phase I then went into dark forward bias exposure in phase II, and vice-versa. After about $120 \mathrm{~h}$ of cumulative exposure, the modules were put again into dark storage for 4 months, after which we began phase III: outdoor deployment for $\sim 6-8$ weeks, for a total accumulated light exposure of 295 $\mathrm{kW}-\mathrm{h} / \mathrm{m}^{2}$, before bringing the modules in for retesting. By performing this step, we hope to capture the nominal outdoor stabilized performance data and how they compare with the indoor stabilization values.

The starting module set is enumerated in Table 1. The first column lists module type, consisting of three types of CdTe modules-A, B, C-plus two types of CIGS modules-A and $B$; second column lists number of modules; and the third column notes any pre-existing exposure. Not all of the modules finished all three phases in this study. The two CdTe B modules failed during phase II (open-circuit); the one pre-exposed CIGS type A failed after dark $90^{\circ} \mathrm{C}$ anneal before phase I, due to low FF. At the end of phases II and III, 8 modules remained.

\begin{tabular}{|r|c|r|}
\hline Module & No. & Pre-existing exposure \\
\hline CdTe A & 2 & Yes, outdoors, hot-humid, 3 years \\
\hline CdTe B & 2 & No, nascent \\
\hline CdTe C & 1 & Yes, indoor light-soak 2002,1130 kWh/m \\
\hline CIGS A & 4 & $\begin{array}{r}\text { No, 3 nascent controls from 2003; } \\
\text { 1 exposed in hot-humid outdoors 3 years }\end{array}$ \\
\hline CIGS B & 2 & No, nascent \\
\hline
\end{tabular}

Table 1 List of study plan modules at start.

Dark and light I-V data were measured on the large-area continuous solar simulator (LACSS) test bed by the Cell and Module Measurements Team at NREL. Light I-V measurements conform to standard test conditions (STC): $25^{\circ} \mathrm{C}, 1000 \mathrm{~W} / \mathrm{m}^{2}$ total irradiance, using IEC 60904-3 $2^{\text {nd }}$ ed. global reference spectrum. Dark I-V data were measured after light I-V, up to $20-30$ volts higher than $V_{O C}$ to attain forward current values above the short-circuit current (Isc). C-V profiles were measured with a precision LCR meter (HP-4284 A), with frequency range $20 \mathrm{~Hz}-$ $1 \mathrm{MHz}$. The $4284 \mathrm{~A}$ supplies both the AC excitation signal and the $D C$ bias voltage $\left(V_{B}\right)$ for the sweep. A Keithley digital multimeter was used to measure the applied DC bias, $V_{B}$, across the module accurately, as the applied $V_{B}$ can be appreciably loaded down by either shunt or diode conductance. The excitation frequencies initially were varied over a wide range to obtain the location where the best (lowest dissipation) high-frequency capacitance signals reside. In spite of popular misconception that module capacitance is too large to measure, we point out that its feasibility is based on the large number of seriesconnected cells in modules, plus the fact that capacitors in series add up as the reciprocal of each capacitor. Also the magnitude of the area of each cell is similar to the number of cells, and so the total module capacitance is equivalent to that of a $\sim 0.5-2 \mathrm{~cm}^{2}$ size cell, provided that cells are uniform enough and there are no pathologically bad cells. 


\section{RESULTS: PERFORMANCE CHANGES}

Figure 2 is a composite-panel graph depicting the relative changes in CdTe modules' power parameters, ( $\left.\eta_{\text {STC }}\right)$, FF, $\mathrm{V}_{\mathrm{OC}}$, and Isc, plotted vs. exposure category, respectively, going from top to bottom panes, in all phases of our study; changes are expressed as percent change relative to baseline data measured in May 2009. The left-most category represents any pre-existing measurements, typically years prior to baseline data; baseline is the second category from left. At baseline, all relative changes are by definition zero. The next two columns represent changes incurred during preconditioning outdoors; after that comes phase I data, which in turn is followed by dark storage; then phase II data, followed by another period of dark storage; and finally phase III data at right. In phase I, A1, B1, and C1 underwent biased dark exposure, while A2 and $B 2$ went through light soaking; these were swapped in phase II with $A 1, B 1$, and $C 1$ in light soak, while $A 2$ and B2 went into dark exposure. The middle two legends of symbols in Fig. 2 indicate which module went into either light or dark exposures in phases I or II.

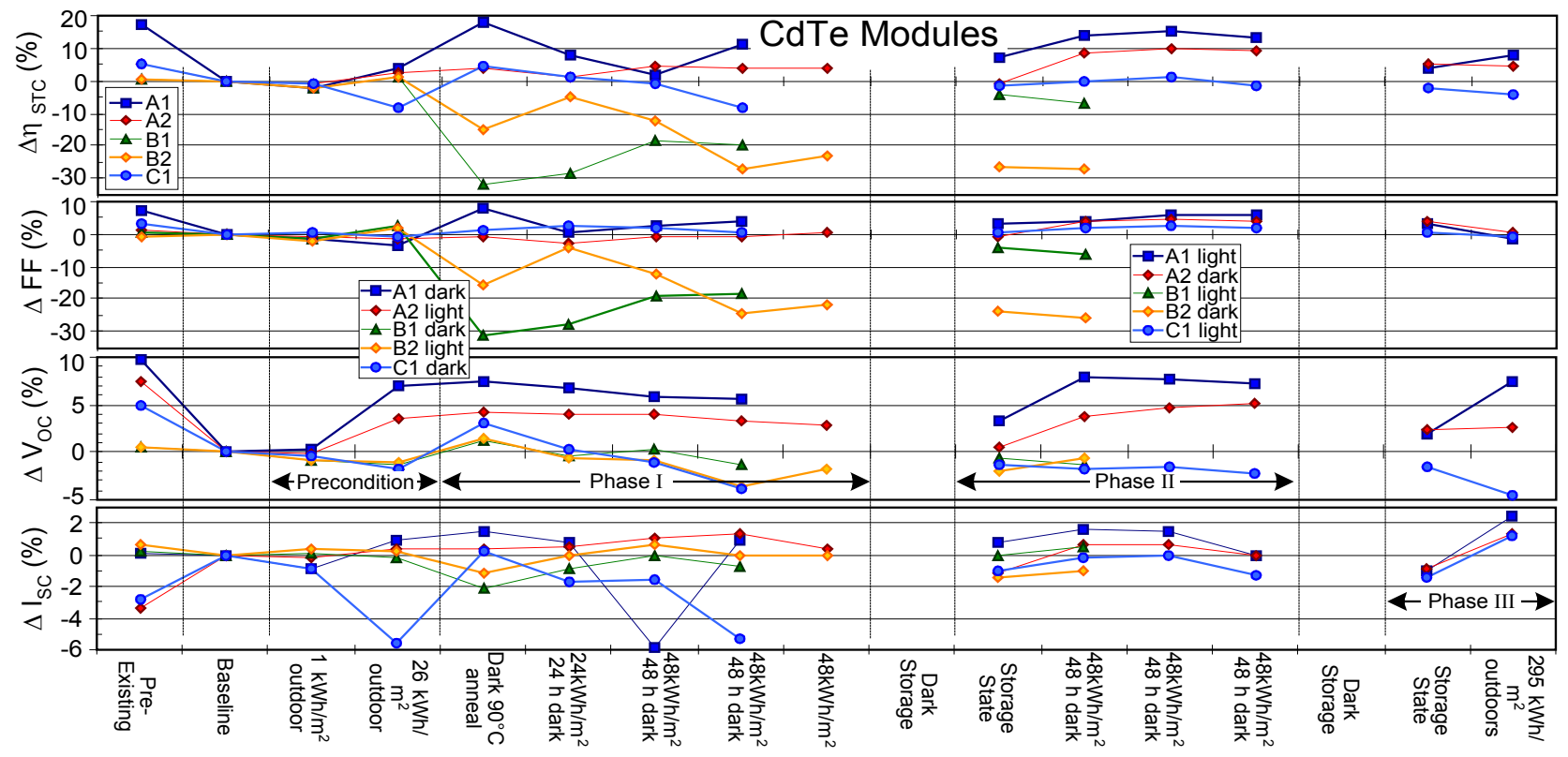

Figure 2 Changes to module efficiency, FF, $V_{O C}$ and $I_{s c}$, respectively going from top to bottom panes, plotted vs. exposure category for CdTe modules A1, A2, B1, B2, and C1, as percent relative to values at baseline, May 2009.

Initially with $1 \mathrm{~kW}-\mathrm{h} / \mathrm{m}^{2}$ outdoor exposure after baseline, there are slight drops in all performance data, from $1 \%$ to $3 \%$. Subsequently, after $26 \mathrm{~kW}-\mathrm{h} / \mathrm{m}^{2}$ outdoor exposure, the $\mathrm{A}$ and $\mathrm{B}$ modules improve, while module $\mathrm{C} 1$ loses about $9 \%$ of its performance. After the $48 \mathrm{~h}$ dark, thermal $\left(90^{\circ} \mathrm{C}\right)$ anneal, the $A$ and $C 1$ modules improve while the $B$ modules' performance degrades. Most improvements are due to increases in $\mathrm{V}_{\mathrm{OC}}$ in dark $90^{\circ} \mathrm{C}$ anneal for all the modules, ranging $1 \%$ to $7 \%$. The A1 module's efficiency improves the most, $\sim 17 \%$ after $90^{\circ} \mathrm{C}$ anneal, to the level it had been years prior to baseline before any exposure, due to increases in both $\mathrm{FF}$ and $\mathrm{V}_{\mathrm{OC}}$. After $90^{\circ} \mathrm{C}$ anneal, the $\mathrm{B}$ modules' performance data decline, which is due predominantly to large FF losses ranging 15\%-30\%.

Afterward, in phase I, biased dark exposure ameliorated the performance (up from that after $90^{\circ} \mathrm{C}$ anneal) of the $\mathrm{B} 1$ module to about $19 \%$ loss relative to baseline; but light soaking ended up degrading the performance of the B2 module close to $\sim 22 \%$ loss relative to baseline. The A1 module performance declines in two subsequent intervals in biased dark exposure, largely as a result of Isc losses in the second interval, which reverse for the third biased-dark interval, ending about $12 \%$ higher in performance than at baseline. The A2 module performance data hardly change after dark thermal anneal to the end of phase I during which it was light-soaked. At the end of phase I, the C1 module performance-exposed in dark forward bias-is nearly identical to that after the outdoor pre-conditioning. In the dark storage intermission between phases I and II, both the A and B2 modules' performance data degrade slightly, with losses in the A modules' $V_{O C}$ data responsible for this drop. During the dark storage, the $\mathrm{C} 1$ and B1 modules' performance data improve due to amelioration of their $\mathrm{V}_{\mathrm{OC}}$ or FF, respectively. Subsequently during phase II, the $\mathrm{A} 1$ and $\mathrm{A} 2$ modules' performance data increase, respectively, while in biased-dark and light-soak exposures due to increases in their $\mathrm{V}_{\mathrm{OC}}$; whereas the $\mathrm{C} 1$ modules' data varies slightly $1 \%-2 \%$ throughout phase II, exhibiting slight increases $(\sim 1 \%)$ in $\mathrm{FF}$ data, and $1.5 \%$ drop concurrently in the $\mathrm{V}_{\mathrm{OC}}$ data. Noteworthy, both $\mathrm{B}$ modules fail in the open-circuit condition during phase II, indicating high series resistance. Infrared images reveal hot spots at the bus bar contacts, and may thus reflect problems not intrinsic to the absorber. In phase II following dark storage, the Isc data appear to increase $\sim 1 \%$ and then decrease $1 \%-2 \%$, respectively, in the first or next two exposure intervals. 
At the beginning of phase III following dark storage, both $\mathrm{A}$ modules' performance seem to degrade largely as a result of decline in $\mathrm{V}_{\mathrm{OC}}$ data. The $\mathrm{C} 1$ module data are largely unchanged during dark storage. The $295 \mathrm{kWh} / \mathrm{m}^{2}$ of outdoor exposure in phase III brings slight improvement in A1 performance $\sim 3 \%$, via increase in $\mathrm{V}_{\mathrm{OC}}$ by about $6 \%$. Module A2 exhibits no change in performance after phase III, while C1 shows $2 \%$ degradation. During phase III, all the FF data exhibit slight degradation of $\sim 1 \%$ to $4 \%$, while all the modules' Isc data show about $4 \%$ improvement. In terms of where performance data end up after phase III, that of $A 1$ and $A 2$ are close to what they were at the end of phase I, respectively, in dark exposure or light-soak. Module C1's performance data end up $\sim 5 \%$ lower than at baseline, and $\sim 5 \%$ higher than at the end of phase I biased dark exposure-close to midway between the ends of phase I and II exposures, respectively, in dark or light exposures.

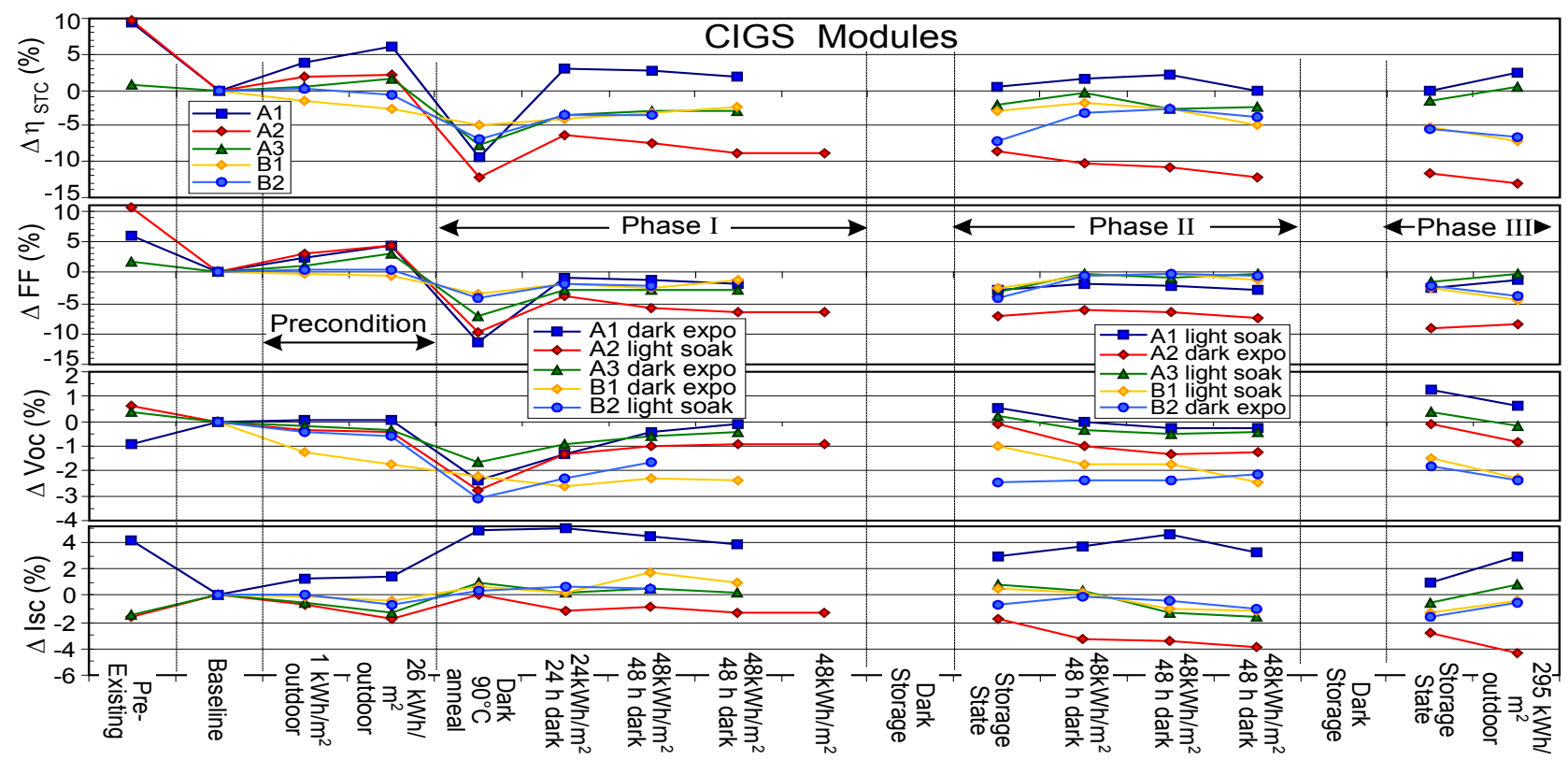

Figure 3 Changes to module efficiency, FF, $V_{o c}$ and Isc, respectively, going from top to bottom panes, plotted vs. exposure category for CIGS modules A1, A2, A3, and B1, B2, as percent relative to values at baseline, May 2009.

The relative changes to CIGS modules' power parameters are portrayed in Fig. 3, which similarly to Fig. 2 is a multipane graph showing the CIGS modules' $\eta_{\text {stc }}$, FF, $V_{O C}$, and Isc data, respectively, going from top to bottom panels, plotted vs. exposure category. The changes are expressed as percent from baseline, the second category from left. The A1, A3, and B2 modules were in biased dark exposure in the first phase, and the $A 2$ and $B 1$ modules were in light exposure in phase I. In phase II, A1, A3, and B2 were light-soaked, while A2 and B2 were in biased dark exposure. In phase II, as mentioned, the forward bias voltages for dark exposure were increased to maintain $\sim I_{\text {MPP }}$ at STC current flowing at $65^{\circ} \mathrm{C}$. Any pre-existing data are shown in the left-most category. After outdoor preconditioning under natural light: the A modules' $\eta_{\text {STC }}$ data improve between $1 \%$ and $6 \%$, largely due to $\mathrm{FF}$ increases; while the B modules' performance degrade slightly $\sim 1 \%-3 \%$ predominantly as a result of loss in $V_{O C}$. For the $\mathrm{A}$ and $\mathrm{B}$ modules, during preconditioning, the $\mathrm{V}_{\mathrm{OC}}$ and $I_{\mathrm{SC}}$ data exhibit ambiguous trends, albeit declining for most except for A1. After the dark thermal anneal, both $A$ and $B$ module performance degrade, due to a combination of losses in FF and $\mathrm{V}_{\mathrm{OC}}$ data, respectively, ranging 3\%$12 \%$ and $2 \%-3 \%$; while the Isc data remain largely flat (except for A1). This degradation behavior of $V_{O C}$ data for the CIGS after dark $90^{\circ} \mathrm{C}$ anneal is contrasted against that of the CdTe modules, which show improved $V_{O C}$ during the same exposure.

In phase I, the A modules in forward bias dark exposure improve more than the A2 module in light-soaking: A1 and A3 recover most of the losses in FF and $V_{O C}$ incurred in dark $90^{\circ} \mathrm{C}$ anneal, while $\mathrm{A} 2$ does not recover as much. For the $\mathrm{B}$ modules, the recovery of sustained losses in FF occurs for both dark and light exposures, but their $V_{O C}$ data do not recover as much as for the A modules. At the end of phase I, the B1 module performance data (dark exposure) are close to that recorded after outdoor preconditioning. All of the other modules $\eta_{\text {stc }}$ data are visibly lower, with that for A2 (light-soak) experiencing the largest net decline, $10 \%$, relative to that after outdoor preconditioning, mostly as a result of loss of FF. The dark storage intermission between phases I and II, induces much smaller metastable changes for the CIGS modules, about $2 \%$ or less, than for the CdTe $A$ an $B$ modules during the same intermission. In phase II, A1 and A3 went into light-soaking, which produced a small $(\leq 2 \%)$, change in performance; A2 underwent biased dark exposure, which had a more profound change dropping about $5 \%$, largely a result of $\mathrm{V}_{\mathrm{OC}}$ and $\mathrm{I}_{\mathrm{SC}}$ losses. Although there 
seems to have been slightly larger metastable change in dark storage for the $B$ modules, performance data for the $B$ modules after the end of phase II are nearly identical to those at the end of phase I, dropping $\sim 5 \%$ relative to baseline, and about $2 \%$ lower than after outdoor preconditioning.

In the dark-storage state at the beginning of phase III, the $A$ and $B$ modules exhibited small $(\leq 2 \%)$ changes in performance from their respective values at the end of phase II. We note that the largest metastable changes in any of the power parameters during dark storage between phases II and III comes via $1 \%$ to $2 \%$ improvement in $\mathrm{V}_{\mathrm{OC}}$ data, and that most of these $V_{O C}$ increases are lost after $295 \mathrm{~kW}-\mathrm{h} / \mathrm{m}^{2}$ outdoor exposure in phase III. By the end of phase III, the A1 and A3 module performance data improved by $2 \%$ over that at dark storage, while that of the A2 and B modules degraded by about $2 \%$. During phase III, we note the slight changes in FF data: ranging 1\%-2\% increases or $2 \%$ decreases, respectively, for $A$ and $B$ modules. IsC data increase by $2 \%$ for $A$ and $B$ modules, except for A2, which loses $2 \%$ of its Isc. Comparing the modules' performance data at the end of phase III relative to that after phase I: the performance of $\mathrm{A} 1$ is nearly identical, that of $A 3$ is about $3 \%$ higher, $A 2$ 's is about $5 \%$ lower, and that of the $B$ modules are about $3 \%-4 \%$ lower.

\section{C-V PROFILING}

From C-V measurements, we deduced the depletion width $\left(W_{D}\right)$ vs. bias voltage, $V_{B}$, (at the cell level) profiles, shown in Fig. 4 for CIGS modules A1 and A2, respectively, at left and right panes, at various states of exposure starting from baseline, proceeding to preconditioning, dark thermal $\left(90^{\circ} \mathrm{C}\right)$ anneal, and the ends of phases I, II, and III. The baseline data are represented by dark blue crosses in both figures, while dark black circles represent $\mathrm{Wd}$ vs. $\mathrm{V}_{B}$ data after dark thermal anneal. For $A 1$, the $W d$ vs. $V_{B}$ profile at baseline extends from 0.33 microns at $0.7 \mathrm{~V}$ in reverse bias down to 0.1 microns at $0.3 \mathrm{~V}$ in forward bias. For CIGS A2, the $W_{D}$ data are about 0.1 microns higher throughout this range. At baseline and $V_{B}=0 \quad V$, the hysteresis in $\mathrm{Wd}$ for the $\mathrm{A} 1$ and $\mathrm{A} 2$ sweeping from reverse into forward bias are, respectively, 0.067 and 0.058 microns. After dark thermal anneal, both $\mathrm{A} 1$ and $\mathrm{A} 2 \mathrm{Wd}$ vs. $V_{B}$ profiles are significantly shifted upward relative to all other profiles after every other exposure, and though not shown, the carrier densities have dropped by about a factor of 5 . Perhaps more significantly, after $90^{\circ} \mathrm{C}$ anneal, the size of the hysteresis in the depletion width for the A1 module doubles to $\sim 0.13$ microns at $V_{B}=0$, while that of A2 increases only to about 0.05 microns. The larger $W_{D}$ hysteresis generated after dark thermal anneal decrease in size with subsequent light or biased-dark exposures, but henceforth always remain larger for the A1 module than for A2. The significance of these variations with exposure and ability to move the edge of the depletion width around with bias may portend higher stability as well as higher efficiency after exposure for A1, even though both modules began this study with similar PV efficiency. It's valuable to point out that either light or biased-dark exposures at $65^{\circ} \mathrm{C}$ brought about somewhat similar changes in $W_{D}$ profiles after dark $90^{\circ} \mathrm{C}$ anneal.

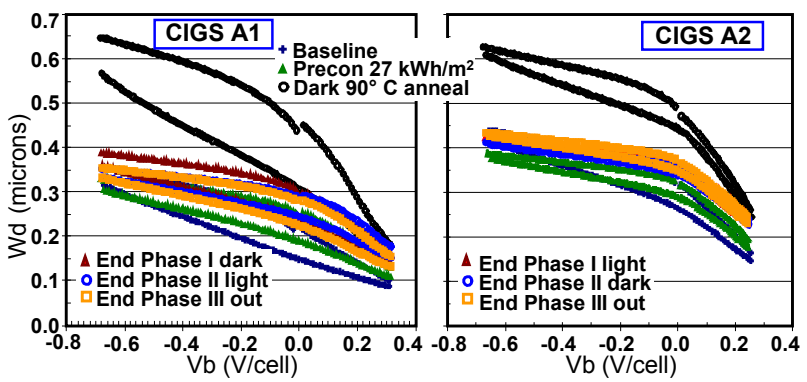

Figure $4 W_{D}$ vs. Vb after various exposures for CIGS $A 1$ and A2, at baseline, after dark thermal anneal and after each of phases I, II, and III.

C-V profiles were also measured for the CdTe modules. For brevity, we do not portray these results graphically, but just note their general features: the dark thermal anneal step displaces the $W_{D}$ profile downward to lower values in contrast to the CIGS modules; the hysteresis in $W_{D}$ profiles appears largely in forward bias in contrast to the CIGS modules where it's largely seen in reverse bias. Either light or biased dark exposures subsequently return the $W_{D}$ profile close to $W_{D}$ values observed near baseline. And larger hysteresis correlates with outdoor exposures.

\section{DISCUSSION}

One of the hypotheses tested in our study is that either light-soaking or forward bias exposure in the dark, at $65^{\circ} \mathrm{C}$, can stabilize performance to within $2 \%$, as called out by IEC 61646 . It appears that at the end of phase I, all the CIGS modules plus the CdTe A2 and B1 modules achieved stability by this definition, which comprises both light and biased-dark exposures. Many of the CdTe modules exhibited large changes in performance $(>2 \%$ relative) while in dark storage between phases I and II. However at the end of phase II, the 3 surviving CdTe modules stabilized equally well in either light or biaseddark exposure. Both of the CdTe B modules failed in the open-circuit mode in phase II, so it's hard to know whether they would have stabilized. In contrast, all the CIGS modules' performance data-except for B2-were largely unchanged during dark storage between any of the phases. Yet at the end of phase II, it also appears that either type of light or dark exposures brought about performance stability, except for CIGS A2. The CIGS A2 module's performance data dropped about $4 \%$ in biaseddark exposure in phase II, plus another $\sim 1 \%$ more upon $295 \mathrm{kWh} / \mathrm{m}^{2}$ outdoor exposure in phase III. This module might actually not be stable, instead of metastable. However well the modules stabilized in indoor light or dark exposures, it is instructive to compare how close their performance data are when stabilized by either indoor or outdoor exposure at the end of phase III, as the latter is the best measure we have relating to their field 
performance. At the end of phase III, the performance of CdTe A2 and C1 modules lie closest- about $2 \%$ away or less-to their respective values at the end of phase I or the end of phase II, respectively, both of which were in light soaking in their respective phases. The performance of $\mathrm{CdTe} A 1$ at the end of phase I, in biased dark exposure, is closer to that at the end of phase III. For the CIGS A1 or A3 modules, in biased-dark exposure in phase I, light-soak in phase II: the performance data of $\mathrm{A} 1$ at the end of phase $\mathrm{I}$ is closer to, and that of $\mathrm{A} 3$ is closer, that at the end of phase III. CIGS A2 performance data continues the same trend in phase III as that in phase II, where it is in biased dark exposure, implying the module is unstable. For the CIGS B2 module, its performance data after either phases I or II are similar to that at the end of phase III, although that after phase II-biased dark exposure-were slightly closer. For CIGS B1, the performance after lightsoaking in phase II is closer. An important consideration is how the performance data compare between that just after initial outdoor preconditioning and the final outdoor exposure in phase III. Here, only the CdTe A2 and CIGS A3 modules' performance data are within $2 \%$ of their respective values.

\section{CONCLUSIONS}

A study plan was devised for testing stabilization of CdTe and CIGS modules indoors and outdoors The data are somewhat inconclusive about whether indoor light-soaking or forward-biased dark exposure brings about faster stabilization, and how close these indoor procedures approach outdoor stabilization. It appears either method is capable of achieving nearly equal results in terms of stability, as after either method was used, many of the modules appear to be stabilized, defined by metric of $2 \%$ or less change in performance. However, compared with longer-term outdoor deployment, neither method seems to achieve better or more accurate results. Yet, it also appears that if forward-bias dark exposure is used, one should favor higher currents-close to $I_{M P P}$-in order to stabilize faster. Furthermore, the results obtained with initial outdoor preconditioning are not better at predicting outdoor performance than the indoor exposure methods. It appears that there may be two time scales (or more) involved in the metastable effects: one that occurs over short times on the order of minutes to hours, that may be saturated by outdoor preconditioning, and another that occurs over a hundred hours or more and that requires elevated temperature and bias to stabilize. Exactly how much remains to be determined, but we have begun to study a second group of CIGS and CdTe modules. Also, there are modules that are unstable and will decay further over much longer time scales. We tested $\mathrm{C}-\mathrm{V}$ profiling on modules successfully, and the data- $W_{D}$ vs. $V_{B}$-correlate with the changes observed during exposure, albeit it remains to be seen whether this may yield predictive information about potential stability issues. For the CIGS A modules, larger displacement or hysteresis of $W_{D}$ vs. $V_{B}$ profile with exposure correlated to higher performance, whereas for CdTe the opposite may be the case.

\section{ACKNOWLEDGEMENT}

This work was supported by the U.S. Department of Energy under Contract No. DOE-AC3608GO28308 with the National Renewable Energy Laboratory.

\section{REFERENCES}

[1] R.A. Sasala, J.R. Sites, "Time dependent voltage in CulnSe2 and CdTe solar cells," Proc. 23rd IEEE PVSC, 1993, pp 543-548.

[2] J.A. del Cueto, B. von Roedern, "Long-term transient and metastable effects in cadmium telluride photovoltaic modules," Prog. Photovolt: Res. Appl 14, 2006 615-628.

[3] S. Hegedus, D. Desai, D. Ryan, B. McCandless, "Transient degradation and recovery of CdTe/CdS solar cells," Proc. $31^{\text {st }}$ IEEE PVSC, Florida, 2005, 319-322.

[4] D. Willett, S. Kuriyagawa, "The effects of sweep rate, voltage bias and light-soaking of CIS-based solar cell characteristics," Proc. 23 ${ }^{\text {rd }}$ IEEE PVSC, 1993, 495-500.

[5] U. Rau, A. Jasenek, R. Herberholz, R., H.-W. Schock, J.-F. Guillemoles, D. Lincot, L. Kronink, "The inherent stability of $\mathrm{Cu}(\mathrm{In}, \mathrm{Ga}) \mathrm{Se} 2-$ based Solar cells," Proc. $2^{\text {nd }}$ WCPEC, Vienna, 1998, 428-433.

[6] P. Zabierowski, U. Rau, M. Igalson, "Classification of metastabilities in the electrical characteristics of $\mathrm{ZnO} / \mathrm{CdS} /$ Cu (In, Ga)Se2 solar cells," Thin Solid Films 387, 2001, 147-150

[7] M. Igalson, M. Cwil, M. Edoff, "Metastabilities in the electrical characteristics of CIGS devices: Experimental results vs theoretical predictions," Thin Solid Films 515, 2007, 6142-6146.

[8] M. Schmidt, D. Braunger, R. Schafler, H. Schock, U. Rau, Thin Solid Films 361-362, 2000, 283-287.

[9] M. Igalson, M. Wimbor, J. Wennenberg, Thin Solid Films 403-404, 2002, 320-324.

[10] D.E. Tarrant, R.R. Gay, "Research on High Efficiency, Large-area CulnSe2-Based Thin-Film Modules," Final Contract Report, NREL/TP-413-8121, 1995, pp. 62-72.

[11] K.D. Dobson K.D., I. Visoly-Fischer, G. Hodes, D. Cahen, Sol. Ener. Mats \& Sol. Cells, 62, 2000, 295-325.

[12] D.S. Albin, R.G. Dhere, S.C. Glynn, J. delCueto, W.K. Metzger, "Degradation and Capacitance-Voltage Hysteresis in CdTe Devices," Proc SPIE Optics \& Photonics Conf., San Diego, CA, 7412, 2009, 1-12.

[13] IEC 61646, "International Standard: Thin-film terrestrial photovoltaic (PV) modules - Design qualification and type approval," Sec. 10.19; International Electrotechnical Commission Central Office 3, rue de Varembé, CH-1211 Geneva 20 Switzerland, $2^{\text {nd }}$ ed., 2008. 


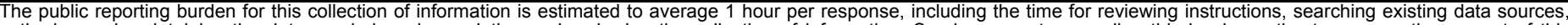

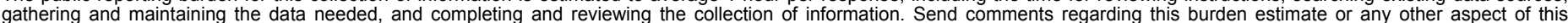

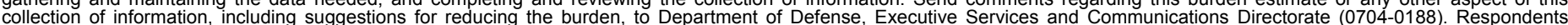

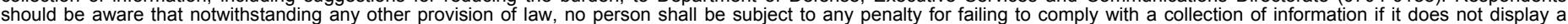

should be aware that notwithstanding

PLEASE DO NOT RETURN YOUR FORM TO THE ABOVE ORGANIZATION.

\section{REPORT DATE (DD-MM-YYYY) 20-06-2010}

4. TITLE AND SUBTITLE

Progress Toward a Stabilization and Preconditioning Protocol for Polycrystalline Thin-Film Photovoltaic Modules
3. DATES COVERED (From - To) June 20-25, 2010

5a. CONTRACT NUMBER

DE-AC36-08-GO28308

5b. GRANT NUMBER

5c. PROGRAM ELEMENT NUMBER

5d. PROJECT NUMBER

NREL/CP-520-47748

5e. TASK NUMBER

PVD9.1430

5f. WORK UNIT NUMBER
7. PERFORMING ORGANIZATION NAME(S) AND ADDRESS(ES)

National Renewable Energy Laboratory

1617 Cole Blvd.

Golden, CO 80401-3393
8. PERFORMING ORGANIZATION REPORT NUMBER

NREL/CP-520-47748

9. SPONSORING/MONITORING AGENCY NAME(S) AND ADDRESS(ES)

10. SPONSOR/MONITOR'S ACRONYM(S) NREL

11. SPONSORING/MONITORING AGENCY REPORT NUMBER

12. DISTRIBUTION AVAILABILITY STATEMENT

National Technical Information Service

U.S. Department of Commerce

5285 Port Royal Road

Springfield, VA 22161

13. SUPPLEMENTARY NOTES

14. ABSTRACT (Maximum 200 Words)

Cadmium telluride (CdTe) and copper indium gallium diselenide (CIGS) thin-film photovoltaic (PV) modules can exhibit substantial variation in measured performance depending on prior exposure history. This study examines the metastable performance changes in these PV modules with the goal of establishing standard preconditioning or stabilization exposure procedures to mitigate measured variations prior to current-voltage (IV) measurements.

15. SUBJECT TERMS

photovoltaic; performance; thin-film modules; CdTe; CIGS; stability; stabilization; preconditioning; metastable behavior

\begin{tabular}{|c|c|c|c|c|}
\hline \multicolumn{3}{|c|}{ 16. SECURITY CLASSIFICATION OF: } & \multirow{2}{*}{$\begin{array}{l}\text { 17. LIMITATION } \\
\text { OF ABSTRACT } \\
\text { UL }\end{array}$} & \multirow{2}{*}{$\begin{array}{ll}\text { 18. } & \text { NUMBER } \\
\text { OF PAGES }\end{array}$} \\
\hline $\begin{array}{l}\text { a. REPORT } \\
\text { Unclassified }\end{array}$ & $\begin{array}{l}\text { b. ABSTRACT } \\
\text { Unclassified }\end{array}$ & $\begin{array}{l}\text { c. THIS PAGE } \\
\text { Unclassified }\end{array}$ & & \\
\hline
\end{tabular}

19a. NAME OF RESPONSIBLE PERSON

19b. TELEPHONE NUMBER (Include area code) 